\title{
Mathematics-related emotions among Finnish adolescents across different performance levels
}

\section{Holm, Marja Eliisa}

2017

Holm , M E , Hannula , M S \& Björn , P M 2017 , ' Mathematics-related emotions among Finnish adolescents across different performance levels ', Educational Psychology : An International Journal of Experimental Educational Psychology , vol. 37 , no. 2 , pp. 205-218 . https://doi.org/10.1080/

http://hdl.handle.net/10138/224161

https://doi.org/10.1080/01443410.2016.1152354

acceptedVersion

Downloaded from Helda, University of Helsinki institutional repository.

This is an electronic reprint of the original article.

This reprint may differ from the original in pagination and typographic detail.

Please cite the original version. 
Mathematics-Related Emotions among Finnish Adolescents across Different Performance Levels

Marja Eliisa Holm and Markku Sakari Hannula University of Helsinki, Finland

Piia Maria Björn

University of Eastern Finland, Finland

Author Note

Marja E. Holm, Faculty of Educational Sciences, University of Helsinki, PO box 9, FI-00014, Helsinki, Finland, marja.hytonen@helsinki.fi; Markku S. Hannula, Faculty of Educational Sciences, University of Helsinki, PO box 9, FI-00014, Helsinki, Finland, markku.hannula@helsinki.fi; Piia M. Björn, School of Educational Sciences and Psychology, University of Eastern Finland, PO box 111, FI-80101, Joensuu, Finland, piia.bjorn@ uef.fi.

This work was supported by scholarships from the Finnish Cultural Foundation. The first author wishes to thank the Finnish Cultural Foundation for these scholarships.

Correspondence concerning this article should be addressed to Marja E. Holm, Faculty of Educational Sciences, University of Helsinki, PO box 9, FI-00014. E-mail: marja.hytonen@helsinki.fi 


\begin{abstract}
This study examined the relation of mathematics performance and gender with seven mathematics-related emotions (enjoyment, pride, anger, anxiety, shame, hopelessness and boredom) among adolescents. Using strict and lenient mathematics performance cut-off scores, respective groups of adolescents with mathematics difficulties (MD, $n=136$ ), low (LA, $n=166$ ) and typical mathematics performance (TA, $n=1056)$ were identified. Our results revealed that the MD group reported more shame than the LA group. The MD group also reported more negative emotions and less positive emotions than the TA group, with the exception of boredom, for which there was no statistically significant difference. The interaction effect between mathematics performance group and gender on emotions was significant. Only females with MD showed significantly higher levels of hopelessness and shame than females with LA, while males with LA even reported more boredom than males with MD. Concerning gender differences, males reported slightly more pride and enjoyment than females. However, the direction and magnitude of the gender differences showed great variance among mathematics performance groups. The practical implications of the results are discussed.
\end{abstract}

Keywords: adolescents, gender, mathematics-related emotions, mathematics performance groups 
Mathematics-Related Emotions among Finnish Adolescents across Different Performance Levels

Mathematics is an important academic skill and many students have emotional experiences related to mathematics. Students might enjoy mathematics class, feel hopelessness during a mathematics test or worry that they will receive a bad mathematics grade (Frenzel, Pekrun, \& Goetz, 2007a). Although various emotions such as shame, boredom, enjoyment, anxiety, pride and hopelessness have been identified in academicrelated situations (Pekrun, Goetz, Titz, \& Perry, 2002), studies examining the interrelationship between emotions and mathematics performance have often focused on anxiety (e.g. Ashcraft \& Krause, 2007; Devine, Fawcett, Dénes, \& Dowker, 2012; Hembree, 1990; Ma, 1999; Miller \& Bichsel, 2004). Mainly students with mathematics difficulties (Passolunghi, 2011; Wu, Willcutt, Escovar, \& Menon, 2014) and with low mathematics performance (Wu et al., 2014) experienced anxiety in mathematics-related situations. However, it is also important to understand other emotional experiences that occur among students with mathematics difficulties and with low mathematics performance. This understanding may help develop teaching methods that support these students in mathematics. Adolescents who are at critical stages of school dropout and academic failure and undergo fundamental changes in emotions, cognitive processes and social relationships (Eccles, 1999) require their emotions to be understood and supported. Mainly adolescents around 15 years of age are at an increased risk of depression (Hankin et al., 1998) and unhappiness (Uusitalo-Malmivaara, 2014), and this risk might be particularly evident among females (Hankin et al., 1998; Uusitalo-Malmivaara, 2014) and students with learning difficulties (Huntington \& Bender, 1993). Thus, this study examined which seven emotional experiences (enjoyment, pride, anger, anxiety, hopelessness, shame and boredom) were 
present among 14-15-year-old adolescents with mathematics difficulties and low and typical mathematics performance, and whether these emotional experiences differ by gender.

\section{Achievement Emotions}

We examined achievement emotions, which are defined on the basis of the control value theory (Pekrun, 2006; Pekrun, Frenzel, Goetz, \& Perry, 2007). These emotions are divided into activity-related achievement emotions experienced in relation to academic activities (e.g. boredom during homework assignments) and outcome-related achievement emotions experienced before or after the academic outcomes such as success and failure (e.g. pride after a successful mathematics exam) (Pekrun, 2006). Achievement emotions are also classified as typically experienced emotions in certain situations (trait achievement emotions) or momentarily experienced emotions in certain situations at a certain time (state achievement emotions) (Pekrun, 2006; Pekrun et al., 2007). The control value theory identifies two key appraisal processes for the formation of achievement emotions. These are subjective control over achievement activities and outcomes (e.g. the expectation that one is able to perform in activities), and the subjective values of activities and outcomes (e.g. the perceived importance of activities and success) (Pekrun, 2006; Pekrun et al., 2007). For example, enjoyment might increase if students experience academic activities as understandable and positively valued, and anxiety might occur if students expected to fail an important mathematics test (Pekrun, 2006).

\section{Low Mathematics Performance and Mathematics-Related Emotions}

An extensive body of research has focused on associations between anxiety and mathematics performance, whereas other emotional experiences are less well researched. Prior research reports have shown a moderately strong negative association between mathematics performance and anxiety over a wide age range (e.g. Ashcraft \& Krause, 2007; Hembree, 1990; Ma, 1999; Miller \& Bichsel, 2004; Wu et al., 2014). Although the 
assumption that mathematics anxiety influences mathematics ability is well supported, some contrary results have occurred (Krinzinger, Kaufmann, \& Willmes, 2009). Krinzinger et al. (2009) found no effect of mathematics anxiety on calculation ability in primary school children. Furthermore, only a few studies have investigated anxiety among students with different mathematics performance levels, and these studies focused only on primary school children (Passolunghi, 2011; Wu et al., 2014). Wu et al. (2014) revealed that second and third grade children with mathematics difficulties (scored below the 11th percentile on the mathematics test) or with low mathematics performance (scored at the 11 th to 24 th percentiles) reported significantly more anxiety than children with typical mathematics performance. However, the first two groups (difficulties and low performance) were not significantly different from one another.

Despite the fact that students at elementary school and university reported experiencing several emotions, such as anxiety, anger, boredom, shame and hopelessness in academic situations (Pekrun et al., 2002), only a few studies have investigated the associations between mathematics performance and emotions other than anxiety (Goetz, Frenzel, Hall, \& Pekrun, 2008; Kim, Park, \& Cozart, 2014; Luo, Lee, Ng, \& Ong, 2014). Goetz et al. (2008) found that final mathematics grades positively predicted enjoyment among students from grades 5 to 10. Kim et al. (2014) revealed that anger was the strongest predictor of high school students' final mathematics grade. Studies investigating several emotions among students with different mathematics performance levels are largely absent (Stephanou, 2011). Stephanou (2011) found that adolescents (15-16 years old) who perceived their mathematics performance as unsuccessful felt less positive emotions, such as pride, and more negative emotions, such as anger, anxiety and boredom, than adolescents who estimated their performance as successful.

\section{Gender Differences in Mathematics-Related Emotions}


The relationship between gender and mathematics anxiety has been studied extensively. Many studies have found that females reported significantly more mathematics anxiety than males (e.g. Devine et al., 2012; Else-Quest, Hyde, \& Linn, 2010; Hembree, 1990; Kyttälä \& Björn, 2010; Miller \& Bichsel, 2004; OECD, 2004; Plenty \& Heubeck, 2013). A cross-national meta-analytic finding indicated that even $94.9 \%$ of the OECD countries showed higher levels of mathematics anxiety among females than males (ElseQuest et al., 2010).

There are a limited number of studies with an emphasis on gender differences in mathematics-related emotions other than anxiety (Frenzel et al., 2007a; Goetz et al., 2008; Stipek \& Gralinski, 1991), and these studies often focused on primary school children. Frenzel et al. (2007a) found that fifth-grade females reported less enjoyment and pride, but more anxiety, hopelessness and shame in mathematics than males. Stipek and Gralinski (1991) revealed that females in the third grade and junior high school reported less pride after mathematics success and more feelings of wanting to hide their paper after mathematics failure than males. However, females were no more likely than males to report shame after mathematics failure or that they wanted to hide their paper after mathematics success. The emotional experiences among females and males with different mathematics performance levels are not understood. Wu et al. (2014) revealed that there are no gender variations in the relation between mathematics performance group (difficulties, low and/or typical) and anxiety (Wu et al., 2014). However, females with reading difficulties (8-18-year olds) reported more depression and anxiety than males with reading difficulties (Willcutt \& Pennington, 2000).

\section{Current Study}

Although a few studies have investigated anxiety among students with mathematics difficulties, to our knowledge no study has examined several emotions among students with 
different mathematics performance levels. The majority of studies on gender differences in mathematics-related emotions have focused on anxiety or investigated gender differences in several emotions in the overall population, which means we lack knowledge about whether there are gender variations in several emotions among students with different mathematics performance levels. Thus, the present study investigated the differences in enjoyment, pride, anger, anxiety, shame, hopelessness and boredom among adolescents with mathematics difficulties, and low and typical mathematics performance. The interaction between gender and mathematics performance group on the seven mathematics-related emotions was also investigated.

Based on the previous results, the following hypotheses were proposed:

Hypothesis 1. Adolescents with mathematics difficulties (Passolunghi, 2011; Wu et al., 2014) and low mathematics performance (Wu et al., 2014) reported more anxiety than adolescents with typical mathematics performance.

Hypothesis 2. There are gender differences in mathematics-related emotions, with females showing a more negative emotional profile than males (Frenzel et al., 2007a; Goetz et al., 2008; Stipek \& Gralinski, 1991), and this gender difference is evident in anxiety (e.g. Devine et al., 2012; Else-Quest et al., 2010; Kyttälä \& Björn, 2010; Miller \& Bichsel, 2004; OECD, 2004; Plenty \& Heubeck, 2013).

Hypothesis 3. There are no gender variations in the relation between mathematics performance group and anxiety (Wu et al., 2014). However, we cannot make assumptions about the relationships among gender, mathematics performance groups, and emotions other than anxiety.

\section{Method}

\section{Participants}


This study comprised 1358 eighth-grade participants (14-15-year olds) from 27 compulsory schools in 5 different provinces in Finland. A geographically representative sample of the schools was compiled as follows: schools were divided into five provinces, and a systematic sample of the schools was selected at regular intervals. There were more schools from the large provinces than from the small ones (Southern Finland: eight schools, Central Finland: nine schools, Eastern Finland: four schools, Oulu: three schools and Lapland: three schools). The study sample included municipalities and cities of different sizes. The school sizes varied representatively from small $(n=65)$ to large $(n=658)$. The Finnish educational system consists of nine years of compulsory schooling (six years of primary school and three years of lower secondary school); in Finland the majority of children begin school during the year they turn seven.

Previous studies have demonstrated that students with mathematics learning disability who scored below the 11 th percentile in the standardized mathematics test differ significantly from students who have low mathematics performance (11th to 25th percentiles) (e.g. Geary, Hoard, Nugent, \& Byrd-Craven, 2008; Mazzocco \& Devlin, 2008; Wu et al., 2014). Thus, it is recommendable to analyse students from these two groups separately to avoid reducing any effects that may be more significant in one of these subgroups (Mazzocco, 2008). It is also essential to compare these two groups to students with typical mathematics performance (Mazzocco, 2008). Thus, we classified adolescents into three groups: 1) mathematics difficulties (MD), 2) low mathematics performance (LA) and 3) typical mathematics performance (TA). We also selected the 11th percentile as the cut-off point for MD since the corresponding score is at the low level on the normative sample of Finnish eighth-grade students (Räsänen \& Leino, 2005) and it might allow a better comparison with other studies using the same percentile as the cut-off point for MD (e.g. Wu et al., 2014). 
Briefly, 136 adolescents met the criteria for students with mathematics difficulties by scoring below the 11 th percentile (0-12, max 40) on a standardized mathematics assessment (Räsänen \& Leino, 2005). A total of 166 adolescents met the criteria for low mathematics performance status by scoring within the 11th-25th percentiles (score range 13-16) on the assessment. The 1056 adolescents who scored above the 25 th percentile (score range 17-40) were assigned to the typically performing group. Table 1 shows the demographic and screening data of adolescents with MD, LA and TA, respectively. The frequencies of males and females across the mathematics performance groups were not significantly different, $\chi^{2}(2, N=1358)=4.68, p=.096$.

Table 1

Demographic and Screening Data across Mathematics Performance Groups

\begin{tabular}{lccc}
\hline & Female & Male & Mathematics performance \\
Group & $n$ & $n$ & $M(S D)$ \\
\hline MD & 76 & 60 & $9.43(2.59)$ \\
LA & 97 & 69 & $14.75(1.11)$ \\
TA & 532 & 524 & $25.54(5.40)$ \\
\hline
\end{tabular}

Note. $\mathrm{MD}=$ mathematics difficulties; LA=low mathematics performance; TA=typical mathematics performance.

\section{Measures}

Mathematics performance. Students' mathematics performance was determined based on a standardized mathematics test developed for the Finnish population (KTLT; Räsänen \& Leino, 2005). The focus of the KTLT test is core mathematics skills in grades 7-9, and it assesses students' performance in arithmetic (e.g. addition, subtraction, multiplication and division), word problems (e.g. solving the tax rate), algebra (e.g. equation solving), geometry (e.g. solving the surface area) and unit conversion (e.g. rounding a large number to the nearest hundred). The test is widely used to screen for potential mathematical difficulties (e.g. Kyttälä, 2008). It is a paper-and-pencil test and contains 40 items, with a correct answer given one point and an incorrect answer given zero points. Thus, the results of the test range from 0 to 40. It has four parallel versions (A, B, C and D) and version B was chosen for this 
study because it was reported to have the highest internal reliability (0.90) (Räsänen \& Leino, 2005). The test correlated significantly with other measures of mathematical skill $(r=.61-$ .78, $p<.001 ;$ Räsänen \& Leino, 2005).

Mathematics-related emotions. To assess students' achievement emotions in mathematics, the Achievement Emotions Questionnaire-Mathematics (AEQ-M; Pekrun, Goetz, \& Frenzel, 2005) was used. The AEQ-M is a self-report instrument designed to assess typical achievement emotions (trait-like emotions) in relation to three mathematics situations (class, learning and test). It contains 60 items measuring 7 emotions: enjoyment, pride, anger, anxiety, shame, hopelessness and boredom. Respondents were asked to express their emotions on a five-point Likert scale ranging from 1 (strongly disagree) to 5 (strongly agree). The AEQ-M was translated into Finnish by a bilingual expert, and pilot tested in a Finnish school. Thirty students from two classes took part in the pilot questionnaire and had an opportunity to give individual feedback. This did not reveal any deficiencies.

\section{Procedure}

The study materials, including written instructions, the KTLT test and the AEQ-M questionnaire were sent to the participant schools $(n=27)$ by regular mail in the spring of 2010. Students completed the AEQ-M questionnaires during the end part of their mathematics lesson, taking approximately 30 min to complete the form. Before completing the questionnaire, students were assured that their responses would be treated confidentially. Concerning the mathematics test, students had 40 min to complete it, and we recommended that all students in a school took the test at the same time. After the completion of the study measurements, the teachers collected all the materials and returned them to the researchers by ordinary mail.

\section{Preliminary Analysis}


Missing data for the AEQ-M items (0.5\%) were not imputed. In addition, 135 students were excluded from the final study sample $(n=1358)$ since they had only taken part in either the KTLT-test $(n=56)$ or the AEQ-M $(n=79)$. The reliabilities of the emotion scales were estimated using Cronbach's alpha coefficients and they ranged from good $(.8 \leq x<.9)$ to excellent $(x \geq .9)$. The reliability of the mathematics test proved to be good (Cronbach's alpha $=.89)$.

\section{Data Analysis}

Two-way MANOVA was performed to test the main effects of the mathematics performance groups, gender and Gender x Group interaction on the emotion scales. Separate ANOVA analyses were conducted to investigate the effects of mathematics performance groups, gender and Gender x Group interaction on each of the emotion scales. Scheffe post hoc tests were used to compare the means of the three mathematics performance groups in each emotion scale. Effect sizes are reported as partial eta-squared $\left(\eta_{\mathrm{p}}{ }^{2}:\right.$ small $\geq .01$, medium $\geq .06$, large $\geq .14$ ) for the MANOVA and ANOVA analyses, and in terms of Cohen's $d$ ( $d$ : small $\geq .2$, medium $\geq .5$ and large $\geq .8$ ) for the post hoc tests (Cohen, 1988).

\section{Results}

Two-way MANOVA pointed out that the mathematics performance group had a significant main effect, $F(14,2302)=8.18, p<.001$, Wilks' lambda $=.91, \eta_{\mathrm{p}}^{2}=.05$, gender had a significant main effect, $F(7,1151)=6.21, p<.001$, Wilks' lambda $=.96, \eta_{\mathrm{p}}{ }^{2}=.04$, and the Gender $x$ Groups interaction had a significant main effect, $F(14,2302)=2.30, p=.004$, Wilks' lambda $=.97, \eta_{\mathrm{p}}^{2}=.01$, on mathematics-related emotion scales.

\section{Mathematics Performance Groups}

As shown in Table 2, there were significant main effects for mathematics performance groups in each emotion scale. The post hoc testing showed that adolescents with MD reported significantly more shame $(p=.025$ and $d=.32)$ than adolescents with LA. The 
MD group also showed less enjoyment $(p<.001$ and $d=-.51)$ and pride $(p<.001$ and $d=-$ $.67)$ and more anger $(p<.001$ and $d=.48)$, anxiety $(p<.001$ and $d=.56)$, shame $(p<.001$ and $d=.60)$ and hopelessness $(p<.001$ and $d=.65)$, but not boredom $(p=.071)$ when compared to adolescents with TA. Adolescents with LA reported significantly less enjoyment $(p<.001$ and $d=-.54)$ and pride $(p<.001$ and $d=-.58)$ and more anger $(p<.001$ and $d=$ $.42)$, anxiety $(p<.001$ and $d=.41)$, shame $(p=.010$ and $d=.28)$, hopelessness $(p<.001$ and $d=.51)$ and boredom $(p=.010, d=.28)$ than adolescents with TA. The effect sizes for boredom and shame were small. Table 3 presents the means and standard deviations for adolescents with different mathematics performances.

Table 2

The Groups, Gender Group x Gender Interaction Effects, and Groups Effects Separately for Females and Males for the Seven Emotion Scales

\begin{tabular}{|c|c|c|c|c|c|c|c|c|c|c|}
\hline \multirow[b]{3}{*}{ Scales } & \multirow{3}{*}{$\begin{array}{l}\text { Groups } \\
\text { F }\end{array}$} & \multirow[b]{3}{*}{$\eta_{\mathrm{p}}^{2}$} & \multicolumn{2}{|c|}{ Gender } & \multicolumn{2}{|c|}{$\begin{array}{l}\text { Group x } \\
\text { Gender }\end{array}$} & \multicolumn{4}{|c|}{ Groups } \\
\hline & & & & & & & Females & & Males & \\
\hline & & & $F$ & $\eta_{\mathrm{p}}^{2}$ & $F$ & $\eta_{p}^{2}$ & $F$ & $\eta_{p}^{2}$ & $F$ & $\eta_{\mathrm{p}}^{2}$ \\
\hline $\mathrm{JO}$ & $25.15^{* * *}$ & .04 & $9.92^{* *}$ & .01 & $4.74^{* *}$ & .01 & $21.42^{* * * *}$ & .07 & $10.02^{* * *}$ & .04 \\
\hline PR & $33.17^{* * *}$ & .05 & $9.54^{* * *}$ & .01 & $3.47^{*}$ & .01 & $28.41^{\text {**** }}$ & .09 & $10.91^{* * *}$ & .04 \\
\hline $\mathrm{AG}$ & $21.98^{* * *}$ & .04 & 1.47 & .00 & $4.40^{*}$ & .01 & $9.57^{* * * *}$ & .03 & $16.27^{* * *}$ & .06 \\
\hline $\mathrm{AX}$ & $25.07^{* * *}$ & .04 & 0.29 & .00 & $6.03^{* *}$ & .01 & $8.51^{* * * *}$ & .03 & $21.98^{* * *}$ & .08 \\
\hline $\mathrm{SH}$ & $21.35^{* * *}$ & .04 & 1.57 & .00 & $3.08^{*}$ & .01 & $11.62^{* * *}$ & .04 & $13.21^{* * *}$ & .05 \\
\hline $\mathrm{HL}$ & $32.74^{* * *}$ & .05 & 2.19 & .00 & $6.48^{* *}$ & .01 & $15.13^{* * *}$ & .05 & $25.74^{* * *}$ & .09 \\
\hline $\mathrm{BO}$ & $7.23^{* *}$ & .01 & 1.25 & .00 & $6.07^{* *}$ & .01 & $4.28^{*}$ & .01 & $8.63^{* * *}$ & .03 \\
\hline
\end{tabular}

Note. $\mathrm{JO}=$ enjoyment; $\mathrm{PR}=$ pride; $\mathrm{AG}=$ anger; $\mathrm{AX}=$ anxiety; $\mathrm{SH}=$ shame; $\mathrm{HL}=$ hopelessness; $\mathrm{BO}=$ boredom. ${ }^{*} p<.0 .5 .{ }^{* *} p<.01 .{ }^{* * * *} p<.001$.

Table 3

Descriptive Statistics for Mathematics Performance Groups on Emotion Scales

\begin{tabular}{lcccccc}
\hline & \multicolumn{2}{c}{ MD } & \multicolumn{2}{c}{ LA } & \multicolumn{2}{c}{ TA } \\
\hline JO & $M$ & $S D$ & $M$ & $S D$ & $S D$ \\
PR & 2.16 & 0.75 & 2.15 & 0.73 & 2.55 & 0.75 \\
AG & 2.46 & 0.87 & 2.57 & 0.76 & 3.04 & 0.85 \\
AX & 2.48 & 0.97 & 2.42 & 0.98 & 2.03 & 0.88 \\
SH & 2.39 & 0.80 & 2.27 & 0.79 & 1.96 & 0.72 \\
HL & 1.99 & 0.75 & 1.76 & 0.70 & 1.57 & 0.64 \\
BO & 2.61 & 1.06 & 2.46 & 1.02 & 1.96 & 0.95 \\
\hline
\end{tabular}

Note. $\mathrm{MD}=$ mathematics difficulties; $\mathrm{LA}=$ low mathematics performance; $\mathrm{TA}=$ typical mathematics performance; $\mathrm{JO}=$ enjoyment; $\mathrm{PR}=$ pride; $\mathrm{AG}=$ anger; $\mathrm{AX}=$ anxiety; $\mathrm{SH}=$ shame; $\mathrm{HL}=$ hopelessness; $\mathrm{BO}=$ boredom. 


\section{Gender}

As presented in Table 2, there was a significant main effect for gender only on enjoyment and pride when mathematics performance groups were controlled for. The effect sizes for enjoyment and pride were small. Males reported slightly more enjoyment (Male: estimated $M=2.41$, Std. Error $=.05$; Female: estimated $M=2.20$, Std. Error $=.04)$ and pride (Male: estimated $M=2.82$, Std. Error $=.06$; Female: estimated $M=2.59$, Std . Error $=.05$ ) than females. When mathematics performance groups were not controlled for, females reported significantly more anxiety, $F(1,1206)=4.23, p=.04, \eta_{\mathrm{p}}^{2}=.003$, and hopelessness, $F(1,1206)=13.54, p<.001, \eta_{\mathrm{p}}{ }^{2}=.01$, and less enjoyment, $F(1,1206)=10.39, p=.001, \eta_{\mathrm{p}}{ }^{2}$ $=.01$, and pride, $F(1,1206)=11.74, p=.001, \eta_{\mathrm{p}}{ }^{2}=.01$, than males. The effect sizes for these emotions, especially for anxiety, were small. Furthermore, males $(M=23.02$ and $S D=7.24$, $\max 40)$ performed better in the mathematics test than females $(M=22.23$ and $S D=7.59)$, but this difference was not significant, $F(1,1356)=3.77, p=.052, \eta_{\mathrm{p}}{ }^{2}=.003$.

\section{Interaction}

As shown in Table 2, the Gender x Group interaction effect was significant for all seven emotion scales. Table 4 presents the means and standard deviations separately for females and males with different mathematics performances. Due to these interaction effects, the gender differences in all emotion scales were investigated separately among the three mathematics performance groups. This analysis revealed that females with MD reported significantly less enjoyment, $F(1,102)=15.14, p<.001, \eta_{\mathrm{p}}{ }^{2}=.13$, and pride, $F(1,102)=$ $11.12, p=.001, \eta_{\mathrm{p}}^{2}=.10$, and more hopelessness, $F(1,102)=5.78, p=.018, \eta_{\mathrm{p}}{ }^{2}=.05$, and boredom, $F(1,102)=5.93, p=.017, \eta_{\mathrm{p}}^{2}=.06$, than males with MD. The gender differences were the other way around among adolescents with LA. Males with LA reported significantly more anger, $F(1,138)=7.61, p=.007, \eta_{\mathrm{p}}^{2}=.05$, anxiety, $F(1,138)=6.59, p=.011, \eta_{\mathrm{p}}{ }^{2}=$ .05 , shame, $F(1,138)=6.02, p=.015, \eta_{\mathrm{p}}^{2}=.04$, and boredom, $F(1,138)=4.05, p=.046, \eta_{\mathrm{p}}^{2}$ 
$=.03$, than females with LA. Females with TA showed significantly higher levels of anxiety, $F(1,917)=6.23, p=.01, \eta_{\mathrm{p}}^{2}=.01$, and hopelessness, $F(1,917)=12.87, p<.001, \eta_{\mathrm{p}}^{2}=.01$, than males with TA, but the effect sizes for these emotions were small. Figure 1 illustrates the gender differences in the seven emotion scales among different mathematics performance groups.

Table 4

Descriptive Statistics for the Mathematics Performance Groups on Emotion Scales Separately for Females and Males

\begin{tabular}{|c|c|c|c|c|c|c|c|c|c|c|c|c|}
\hline \multirow[b]{3}{*}{ Scales } & \multicolumn{6}{|c|}{ Female } & \multicolumn{6}{|c|}{ Male } \\
\hline & \multicolumn{2}{|c|}{ MD } & \multicolumn{2}{|c|}{ LA } & \multicolumn{2}{|c|}{ TA } & \multicolumn{2}{|c|}{ MD } & \multicolumn{2}{|c|}{ LA } & \multicolumn{2}{|c|}{ TA } \\
\hline & $M$ & $S D$ & $M$ & $S D$ & $M$ & $S D$ & $M$ & $S D$ & $M$ & $S D$ & $M$ & $S D$ \\
\hline $\mathrm{JO}$ & 1.93 & 0.66 & 2.15 & 0.72 & 2.51 & 0.76 & 2.47 & 0.77 & 2.14 & 0.76 & 2.60 & 0.75 \\
\hline PR & 2.23 & 0.82 & 2.56 & 0.72 & 2.99 & 0.84 & 2.78 & 0.85 & 2.59 & 0.83 & 3.10 & 0.86 \\
\hline $\mathrm{AG}$ & 2.54 & 1.06 & 2.23 & 0.85 & 2.03 & 0.89 & 2.39 & 0.84 & 2.68 & 1.08 & 2.03 & 0.87 \\
\hline$A X$ & 2.43 & 0.81 & 2.13 & 0.70 & 2.02 & 0.74 & 2.32 & 0.79 & 2.47 & 0.87 & 1.90 & 0.68 \\
\hline $\mathrm{SH}$ & 2.02 & 0.77 & 1.63 & 0.66 & 1.57 & 0.67 & 1.95 & 0.73 & 1.92 & 0.72 & 1.58 & 0.61 \\
\hline HL & 2.82 & 1.12 & 2.31 & 0.97 & 2.07 & 1.02 & 2.33 & 0.91 & 2.65 & 1.07 & 1.85 & 0.85 \\
\hline $\mathrm{BO}$ & 2.83 & 1.13 & 2.52 & 0.92 & 2.44 & 0.94 & 2.32 & 0.92 & 2.86 & 1.07 & 2.32 & 0.92 \\
\hline
\end{tabular}

Note. $\mathrm{MD}=$ mathematics difficulties; $\mathrm{LA}=$ low mathematics performance; TA=typical mathematics performance; $\mathrm{JO}=$ enjoyment; $\mathrm{PR}=$ pride; $\mathrm{AG}=$ anger; $\mathrm{AX}=$ anxiety; $\mathrm{SH}=$ shame; $\mathrm{HL}=$ hopelessness; $\mathrm{BO}=$ boredom.

As significant interaction effects were observed, the differences in emotion scales among the three mathematics performance groups were also investigated separately for males and females. As shown in Table 2, there were significant main effects for mathematics performance groups in each emotion scale for females. The post hoc testing showed that mainly females with MD reported negative emotions in mathematics. Females with MD reported significantly more shame $(p=.004$ and $d=.54)$ and hopelessness $(p=.015$ and $d=$ .49) than females with LA. Females with MD also reported significantly less enjoyment $(p<$ .001 and $d=-.81)$ and pride $(p<.001$ and $d=-.92)$ and more anger $(p<.001$ and $d=.52)$, anxiety $(p<.001$ and $d=.53)$, shame $(p<.001$ and $d=.62)$, hopelessness $(p<.001$ and $d=$ $.70)$ and slightly more boredom $(p=.015$ and $d=.38)$ than females with TA. Females with LA only showed significantly lower levels of pride $(p<.001$ and $d=-.48)$ and enjoyment $(p<$ .001 and $d=-.55)$ than females with TA. 


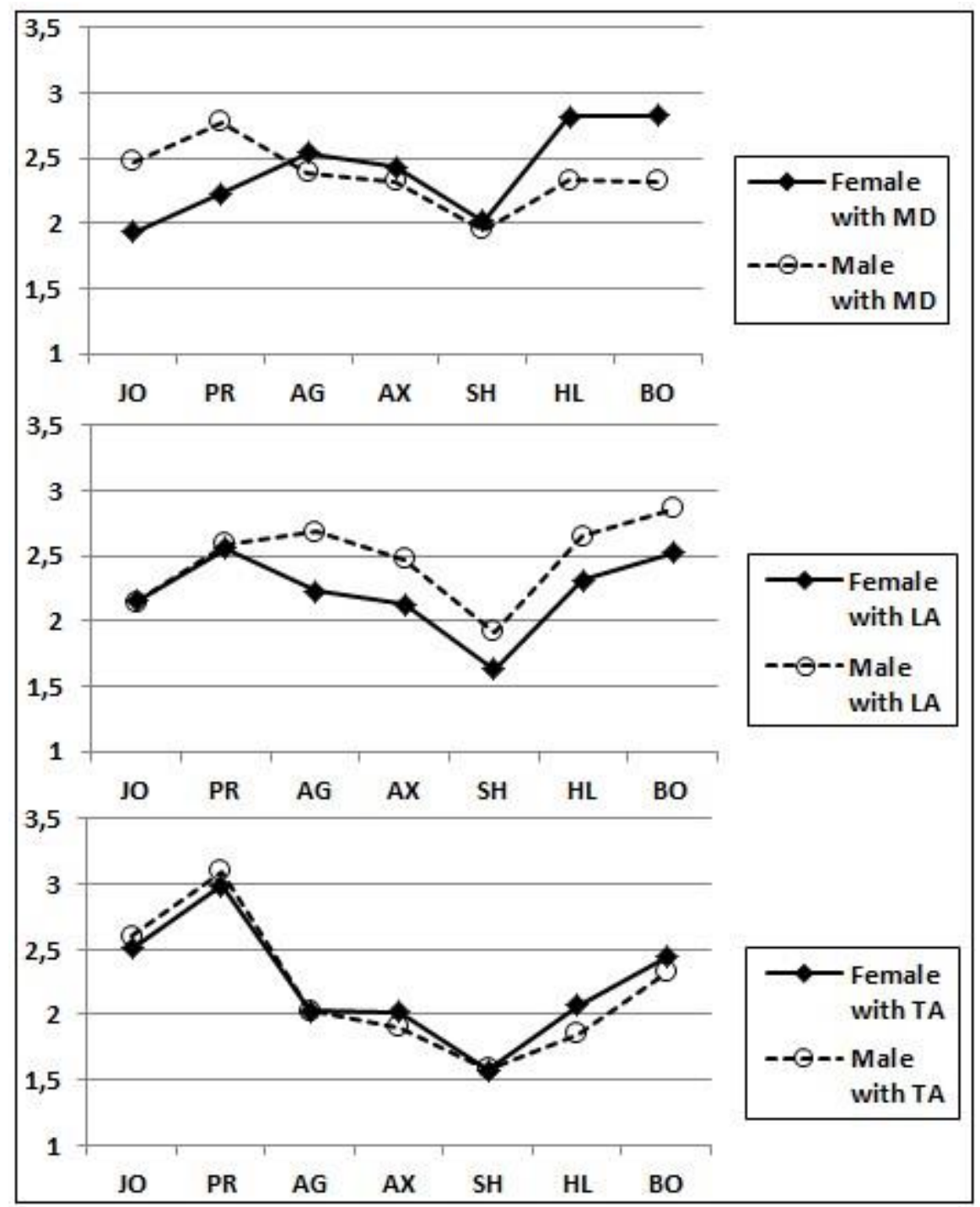

Figure 1. Gender differences in emotions separately for the three mathematics performance groups. $\mathrm{MD}=$ mathematics difficulties; $\mathrm{LA}=$ low mathematics performance; $\mathrm{TA}=$ typical mathematics performance; $\mathrm{JO}=$ enjoyment; $\mathrm{PR}=$ pride; $\mathrm{AG}=$ anger; $\mathrm{AX}=$ anxiety; $\mathrm{SH}=$ shame; $\mathrm{HL}=$ hopelessness; $\mathrm{BO}=$ boredom.

As presented in Table 2, there were significant main effects for mathematics performance groups in each emotion scale for males. The post hoc testing showed that mainly males with LA experience negative emotions in mathematics. Males with LA reported significantly more boredom $(p=.016$ and $d=.54)$ than males with MD, and more anger $(p<$ .001 and $d=.66)$, anxiety $(p<.001$ and $d=.73)$, shame $(p<.001$ and $d=.51)$, hopelessness $(p<.001$ and $d=.83)$, and boredom $(p<.001$ and $d=.54)$, and less enjoyment $(p<.001$ and $d=-.61)$ and pride $(p<.001$ and $d=-.60)$ than males with TA. Males with MD reported significantly more anger $(p=.038$ and $d=.42)$, anxiety $(p=.001$ and $d=.57)$, shame $(p=$ 
.001 and $d=.55)$ and hopelessness $(p=.003$ and $d=.55)$ than males with TA. Figure 2 illustrates the differences among the three mathematics performance groups in the seven emotion scales separately for females and males.

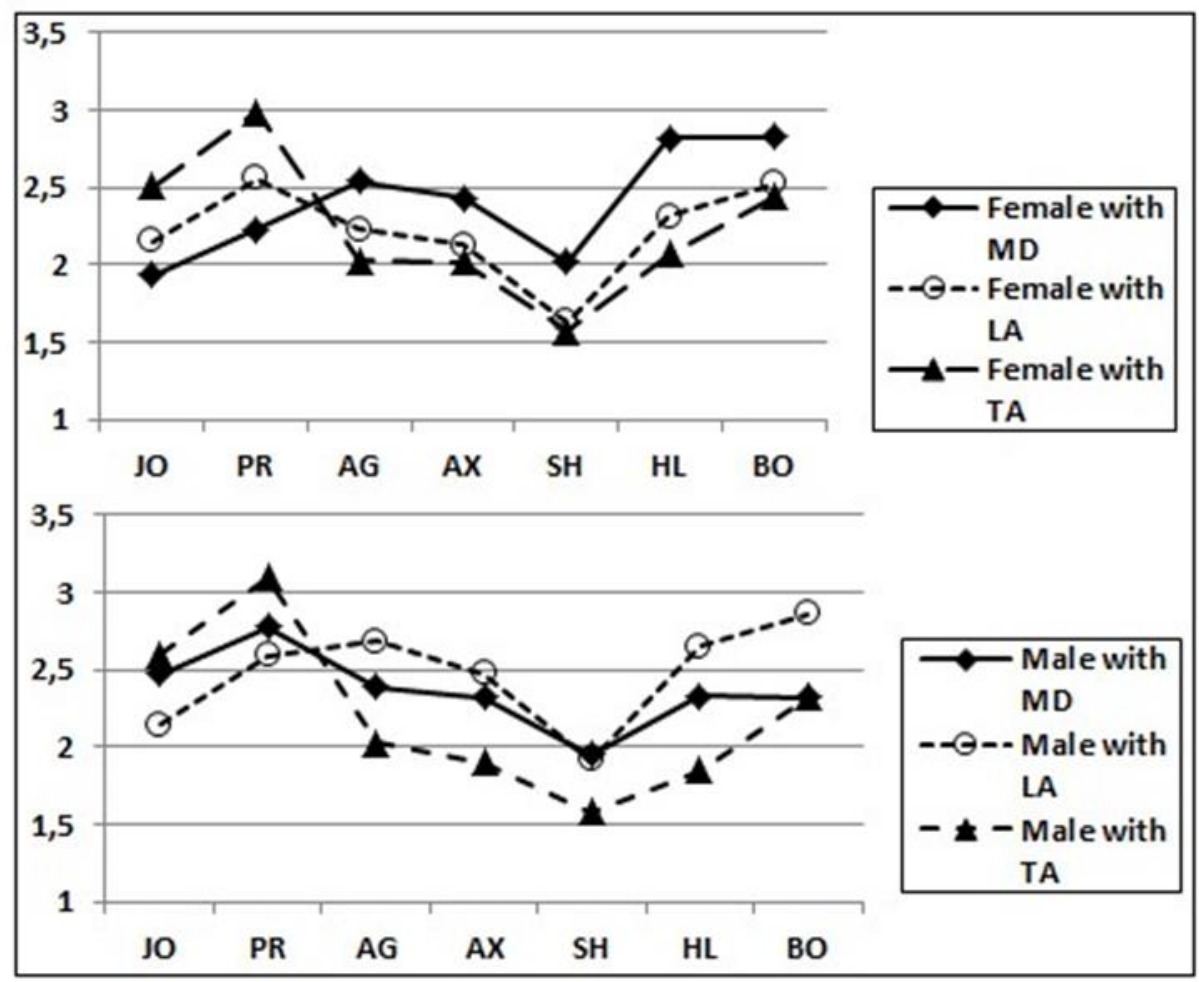

Figure 2. Differences in emotions among three mathematics performance groups for females and males separately. $\mathrm{MD}=$ mathematics difficulties; $\mathrm{LA}=$ low mathematics performance; $\mathrm{TA}=$ typical mathematics performance; $\mathrm{JO}=$ enjoyment; $\mathrm{PR}=$ pride; $\mathrm{AG}=$ anger; $\mathrm{AX}=$ anxiety; $\mathrm{SH}=$ shame; $\mathrm{HL}=$ hopelessness; $\mathrm{BO}=$ boredom.

\section{Discussion}

Although a few studies have shown that children with mathematics difficulties or with low mathematics performance report more anxiety than children with typical mathematics performance (Passolunghi, 2011; Wu et al., 2014), it is clear that they also experience other emotions in the mathematics context. Therefore, our research sought to identify a great variety of emotions among students with mathematics difficulties and with low mathematics performance.

We found that only shame distinguishes adolescents with mathematics difficulties from adolescents with low mathematics performance. Our results support the finding of $\mathrm{Wu}$ 
et al. (2014), which showed no significant difference in anxiety between children with mathematics difficulties and low mathematics performance in a sample from the USA. Although Kim et al. (2014) found that anger predicted students' mathematics grade more than shame, our results suggested that shame is a central emotion among students with mathematics difficulties. Shame rather than the often studied anxiety (e.g. Ashcraft \& Krause, 2007; Devine et al., 2012; Hembree, 1990; Ma, 1999; Miller \& Bichsel, 2004) is important to note when supporting adolescents with mathematics difficulties. However, these findings differ by gender. In our Finnish data, it was mainly females with mathematics difficulties who reported more hopelessness and shame than females with low mathematics performance. On the other hand, males with mathematics difficulties reported less negative emotions and more positive emotions than males with low mathematics performance, although only the difference in boredom was significant. Thus, our study suggested that mainly females with mathematics difficulties and males with low mathematics performance might have a negative emotional profile in mathematics.

Our results support and extend the hypothesis that students with mathematics difficulties and with low mathematics performance report more anxiety than their typically performing peers (Passolunghi, 2011; Wu et al., 2014). In fact, our study found that there were significant differences in several emotions such as enjoyment, pride, anger, anxiety, shame and hopelessness among these groups. This is in line with the results of Stephanou (2011), showing that adolescents who perceived their mathematics performance as unsuccessful reported less positive emotions (e.g. pride) and more negative emotions (e.g. anger, anxiety and boredom) than students who estimated their performance as successful. Our results also indicated that the difference in boredom between adolescents with mathematics difficulties and typical mathematics performance was not significant, and it was only marginally significant between adolescents with low and typical mathematics 
performance. Boredom might occur in challenging and under-challenging (Acee et al., 2010; Daschmann, Goetz, \& Stupnisky, 2011; Pekrun, 2006), as well as monotonous, meaningless and not valuable (Daschmann et al., 2011) mathematics situations. Students with typical mathematics performance might experience boredom if they perceive that mathematics is monotonous, meaningless, under-challenging and not valuable.

Our results did not support the hypothesis that there are no gender variations in the relation between mathematics performance group and anxiety (Wu et al., 2014). In fact, we found that there was a significant interaction between gender and mathematics performance group in all emotions. However, our hypothesis is based on one study focused on primary school children (Wu et al., 2014). Furthermore, as the sample sizes of the mathematics performance groups were small in this study, a significant result may be difficult to achieve. More specifically, our results indicated that mainly females with mathematics difficulties reported less positive emotions and more negative emotions than females with typical mathematics performance, while males with mathematics difficulties reported more anger, anxiety, shame and hopelessness than males with typical performance. On the other hand, mainly males with low mathematics performance reported more negative emotions and less positive emotions than males with typical performance, while females with low mathematics performance showed only lower levels of pride and enjoyment than females with typical mathematics performance. These findings confirm our previously presented suggestion that mainly females with mathematics difficulties and males with low mathematics performance have a negative emotional profile towards mathematics.

Our study revealed that hopelessness, pride and enjoyment were the most powerful components in discriminating mathematics performance groups from each other among females, but anxiety, hopeless and anger were the most powerful among males. Although anger (Kim et al., 2014), enjoyment (Goetz et al., 2008; Kim et al., 2014), pride and anxiety 
(Luo et al., 2014) have been associated with mathematics performance, our study suggested that there are gender variations in these emotions among different mathematics performance groups. We found that hopelessness is the essential component in discriminating mathematics performance groups for both genders. Therefore, adolescents with mathematics difficulties and with low mathematics performance might benefit from emotional support that addresses their experiences of hopelessness in mathematics situations. As students who experience hopelessness might perceive that their failure in mathematics is certain (Pekrun, 2006), it is crucial for teachers to encourage females and males who struggle with mathematics, and give them mathematics problems that they can solve. If students who struggle with mathematics experience success in mathematics learning, their emotions and attitudes may change dramatically from negative to positive (Hannula, 2002).

Our results support the hypothesis that females showed a more negative emotional profile in mathematics than males to a certain extent. We found that females only reported less enjoyment and pride than males when mathematics performance groups were controlled for. This is consistent with previous studies, which indicated that males reported more pride (Frenzel et al., 2007a; Stipek \& Gralinski, 1991) and enjoyment (Frenzel et al., 2007a; Goetz et al., 2008) in mathematics than females. Despite the fact that gender differences in anxiety have been found in several studies (e.g. Devine et al., 2012; Else-Quest et al., 2010; Hembree, 1990; Kyttälä \& Björn, 2010; OECD, 2004; Plenty \& Heubeck, 2013), our study did not find gender differences in anxiety after mathematics performance groups were controlled for. When the mathematics performance groups were not held constant, we found that females reported slightly more anxiety and hopelessness, and less pride and enjoyment than males. Thus, we can conclude that the common finding that females are more anxious than males (e.g. OECD, 2004) is valid among Finnish adolescents when the mathematics performance levels were not taken into account. Our study also found that males performed 
slightly but not significantly better on the mathematics test than females. This is in accordance with previous studies indicating that gender differences in mathematics performance are often small (e.g. Else-Quest et al., 2010; OECD, 2014).

However, we found that the gender differences varied among the mathematics performance groups. Females with mathematics difficulties reported less enjoyment and pride, and more hopelessness and boredom than males with mathematics difficulties. Frenzel et al. (2007a) found that females reported more hopelessness, and less pride and enjoyment in the overall population. Our findings suggested that these gender differences become particularly apparent among students with mathematics difficulties. Although previous research has constantly revealed that females reported more negative emotions (mainly anxiety) than males in mathematics (e.g. Else-Quest et al., 2010; Frenzel et al., 2007a; Hembree, 1990; Kyttälä \& Björn, 2010; OECD, 2004; Plenty \& Heubeck, 2013; Stipek \& Gralinski, 1991), our findings revealed that this is not evident among adolescents with low mathematics performance. We found that males with low mathematics performance reported more anger, anxiety, shame and boredom than females with low mathematics performance. Furthermore, females with typical mathematics performance reported only slightly more anxiety and hopelessness than males with typical mathematics performance.

Researchers have suggested several explanations for why females have more negative emotional profiles in mathematics than males. The gender differences in emotions have often been explained by the theory of stereotype threat (Spencer, Steele, \& Quinn, 1999), which indicates that females are at risk of being judged by the stereotype that they have weaker mathematics ability than males, and that is why females may experience more negative emotions than males (Osborne, 2007). As our results revealed that mainly females with mathematics difficulties reported negative emotions in mathematics, these females might be at great risk of this stereotype threat. Females' low competence beliefs and low domain value 
of mathematics might be responsible for their negative emotional profile in mathematics (Frenzel et al., 2007a). Perhaps, mainly females with mathematics difficulties have low competence and value beliefs in mathematics. Roberts (1991) argued that females may view academic situations as offering an opportunity to receive feedback about their performance. Therefore, females may experience negative feedback as a diagnostic and this can cause them negative emotions about their performance (Pomerantz, Altermatt, \& Saxon, 2002). These findings might suggest that females with mathematics difficulties are sensitive to negative feedback from their teachers, and thus, they have negative emotional profiles in mathematics. Pomerantz et al. (2002) also proposed that females have a great concern about whether they have achieved and earned approval from their teachers. This concern may be reflected not only as a tendency for females to work hard to please teachers, but also to feel negative emotions when they fail and disappoint their teachers (Pomerantz et al., 2002). Perhaps, particularly females with mathematics difficulties suffer from this phenomenon. As mainly females with mathematics difficulties reported hopelessness and low levels of pride in mathematics when compared to other study groups, it is crucial that they have an opportunity to succeed in mathematics, so that they can move on from this circle of negative emotions. The control value theory states that hopelessness and low levels of pride might occur if failure is perceived as certain or success unattainable (Pekrun, 2006).

But why did males with low mathematics performance report a surprising degree of negative emotions in mathematics, and males with mathematics difficulties did not? This may be because mathematics is stereotyped as a male domain (Spencer et al., 1999). Hence, it could be argued that males with low mathematics performance who are below typical performance perceived that they should be better at mathematics, and thus, they experienced negative emotions in mathematics. As mainly males with low mathematics performance reported anger in mathematics when compared to other study groups, it is essential that they 
experience meaningful activities and perceive that their mathematics success is self-inflicted. The control value theory determines that anger might occur if the controllable activities are not valuable or failure is perceived as being caused by others (Pekrun, 2006). On the other hand, males with mathematics difficulties might have less pressure to perform well and meet the requirements in mathematics, and therefore, they may not experience negative emotions in mathematics. Willcutt and Pennington (2000) revealed that males with reading difficulties reported more aggression, inattention, hyperactivity and impulsivity behaviours, but less depression and anxiety than females. Perhaps males with mathematics difficulties also exhibit more problems with behaviour than with emotions, and thus, they may not experience negative emotions in mathematics. Surprisingly, our study revealed that males with mathematics difficulties did not differ in enjoyment, pride and boredom from males with typical mathematics performance, and mainly enjoyment and low levels of boredom were characteristic for them. These males might experience enjoyment but not boredom in mathematics, as they perceive mathematics activities as valuable and controllable (Pekrun, 2006) and they receive appropriate support during mathematics activities. In fact, Willcutt and Pennington (2000) suggested that males with reading difficulties are identified more frequently by parents and teachers as in need of attention and support since they might act in a disruptive manner. This might also be true among males with mathematics difficulties. In future, we need to further our understanding of why females and males with different mathematics performance levels experience negative emotions about mathematics.

The current study observed emotions among Finnish adolescents, which may limit the generalisability of the findings to different cultures. As Finnish students tend to perform very well on international comparisons (OECD, 2014), it might be that the mathematics difficulties group in Finland does not correspond to other countries. However, we have used stricter criteria to identify the group with mathematics difficulties than other Finnish studies 
using the same mathematics test (see, e.g. Kyttälä, 2008) and reached a similar percentage of these students as other studies using quite similar criteria to identify students with mathematics difficulties (Mazzocco \& Devlin, 2008). Furthermore, the results of the gender differences in emotions may be due to females' and males' tendencies and willingness to report different emotions rather than differences in the frequency of emotional experiences. The social acceptability of different emotions (Brody, 2000) or the stereotype that females feel emotions more intensively than males (Grossman \& Wood, 1993) might have influenced this willingness. Anger and pride might be acceptable for males and shame might be acceptable for females (Brody, 2000). However, the direction and magnitude of gender differences in emotions varied according to the three mathematics performance groups. The additional analysis also showed that there was only a marginally significant difference in pride between females with mathematics difficulties and males with low mathematics performance. Thus, the results are impossible to explain on the basis that females and males have a willingness to admit specific emotions. As the study was administered at only one point in time, it is possible that students' emotional experiences at that time affected their responses. The present study was cross-sectional, hence it is difficult to define whether the emotions were the result or cause of mathematics performance, and this causality might even vary according to emotions, mathematics performance groups and gender. However, the general conclusion is that the emotions and academic performance are linked by reciprocal causation (Pekrun et al., 2002).

\section{Practical Implications}

The current study extends previous research by examining several emotions among adolescents with different mathematics performance levels. Our study suggested that mainly females with mathematics difficulties and males with low mathematics performance have negative emotional profiles in mathematics. It is crucial to note that the gender differences in 
emotions vary according to the mathematics performance groups. Mainly females with mathematics difficulties experienced more negative emotions than males with mathematics difficulties, while the gender differences in emotions were the other way around among adolescents with low mathematics performance. Thus, our results suggested that the general perception that females experience more negative emotions in mathematics is not quite true.

Based on our results, it is also safe to say that it is crucial to support the emotional experiences of adolescents struggling with mathematics. Teachers' enjoyment, enthusiasm (Frenzel, Goetz, Lüdtke, Pekrun, \& Sutton, 2009) and affective support (e.g. caring and listening) (Sakiz, Pape, \& Hoy, 2012; Sakiz, 2012), as well as a stress-free and supportive mathematics learning environment (Frenzel, Pekrun, \& Goetz, 2007b) can play a key role in supporting students with a negative emotional profile.

It is essential to note that boredom was not a key component in mathematics difficulties. Students who experienced boredom in mathematics did not necessarily have mathematics difficulties. In order to prevent boredom, it is crucial that teachers use a variety of teaching methods, integrate mathematics into students' everyday lives and also give students sufficient challenges in mathematics (see Daschmann et al., 2011). Such activities are important since boredom was most frequently identified as a reason for leaving school (Bridgeland, Dilulio, \& Morison, 2006). 


\section{References}

Acee, T. W., Kim, H., Kim, H. J., Kim, J.-I., Chu, H.-N. R., Kim, M., Cho, Y., \& Wicker, F. W. (2010). Academic boredom in under- and over-challenging situations. Contemporary Educational Psychology, 35, 17-27. doi:10.1016/j.cedpsych.2009.08.002

Ashcraft, M. H., \& Krause, J. A. (2007). Working memory, math performance, and math anxiety. Psychonomic Bulletin \& Review, 14, 243-248. doi:10.3758/BF03194059

Bridgeland, J. M., Dilulio, J. J., \& Morison, K. B. (2006). The silent epidemic: Perspectives of high school dropouts [Adobe Digital Editions version]. Retrieved from https://docs.gatesfoundation.org/Documents/TheSilentEpidemic3-06Final.pdf

Brody, L. R. (2000). The socialization of gender differences in emotional expression: Display rules, infant temperament, and differentiation. In A. H. Fischer (ed.), Gender and Emotion: Social Psychological Perspectives (pp. 24-47). New York: Cambridge University Press.

Cohen, J. (1988). Statistical power analysis for the behavioral sciences (2nd ed.). Hillsdale, NJ: Erlbaum.

Daschmann, E. C., Goetz, T., \& Stupnisky, R. H. (2011). Testing the predictors of boredom at school: Development and validation of the precursors to boredom scales. British Journal of Educational Psychology, 81, 421-440. doi:10.1348/000709910X526038

Devine, A., Fawcett, K., Dénes S., \& Dowker, A. (2012). Gender differences in mathematics anxiety and the relation to mathematics performance while controlling for test anxiety. Behavioral \& Brain Functions, 8, 1-9. doi:10.1186/1744-9081-8-33

Eccles, J. S. (1999). The development of children ages 6 to 14. The Future of Children, 9(2), 30-44. Retrieved from https://www.princeton.edu/futureofchildren/index.xml 
Else-Quest, N. M., Hyde, J. S., \& Linn, M. C. (2010). Cross-national patterns of gender differences in mathematics: A meta-analysis. Psychological Bulletin, 136, 103-127. doi:10.1037/a0018053

Frenzel, A. C., Goetz, T., Lüdtke, O., Pekrun, R., \& Sutton, R. E. (2009). Emotional transmission in the classroom: Exploring the relationship between teacher and student enjoyment. Journal of Educational Psychology, 101, 705-716. doi:10.1037/a0014695

Frenzel, A. C., Pekrun, R., \& Goetz, T. (2007a). Girls and mathematics - A "hopeless" issue? A control-value approach to gender differences in emotions towards mathematics. European Journal of Psychology of Education, 22, 497-514. doi:10.1007/BF03173468

Frenzel, A. C., Pekrun, R., \& Goetz, T. (2007b). Perceived learning environment and students' emotional experiences: A multilevel analysis of mathematics classrooms. Learning \& Instruction, 17, 478-493. doi:10.1016/j.learninstruc.2007.09.001

Geary, D. C., Hoard, M. K., Nugent, L., \& Byrd-Craven, J. (2008). Development of number line representations in children with mathematical learning disability. Developmental Neuropsychology, 33, 277-299. doi:10.1080/87565640801982361

Goetz, T., Frenzel, A. C., Hall, N. C., \& Pekrun, R. (2008). Antecedents of academic emotions: Testing the internal/external frame of reference model for academic enjoyment. Contemporary Educational Psychology, 33, 9-33. doi:10.1016/j.cedpsych.2006.12.002

Grossman, M., \& Wood, W. (1993). Sex differences in intensity of emotional experience: A social role interpretation. Journal of Personality and Social Psychology, 65, 10101022. doi:10.1037//0022-3514.65.5.1010

Hankin, B. L., Abramson, L. Y., Moffitt, T. E., Silva, P. A., McGee, R., \& Angell, K. E. (1998). Development of depression from preadolescence to young adulthood: 
Emerging gender differences in a 10-year longitudinal study. Journal of Abnormal Psychology, 107, 128-140. doi:10.1037/0021-843X.107.1.128

Hannula, M. S. (2002). Attitude towards mathematics: emotions, expectations and values. Educational Studies in Mathematics, 49, 25-46. doi:10.1023/A:1016048823497

Hembree, R. (1990). The nature, effects, and relief of mathematics anxiety. Journal for Research in Mathematics Education, 21, 33-46. doi:10.2307/749455

Huntington, D. D., \& Bender, W. N. (1993). Adolescents with learning disabilities at risk? Emotional well-being, depression, suicide. Journal of Learning Disabilities, 26, 159166. doi:10.1177/002221949302600303

Kim, C., Park, S. W., \& Cozart, J. (2014). Affective and motivational factors of learning in online mathematics courses. British Journal of Educational Technology, 45, 171-185. doi:10.1111/j.1467-8535.2012.01382.x.

Krinzinger, H., Kaufmann, L., \& Willmes, K. (2009). Math anxiety and math ability in early primary school years. Journal of Psychoeducational Assessment, 27, 206-225. doi:10.1177/ 0734282908330583

Kyttälä, M. (2008). Visuospatial working memory in adolescents with poor performance in mathematics: variation depending on reading skills. Educational Psychology, 28, 273-289. doi:10.1080/01443410701532305

Kyttälä, M., \& Björn, P. M. (2010). Prior mathematics achievement, cognitive appraisals and anxiety as predictors of Finnish students' later mathematics performance and career orientation. Educational Psychology, 30, 431-448. doi:10.1080/01443411003724491

Luo, W., Lee, K., Ng, P. T., \& Ong, J. X. W. (2014). Incremental beliefs of ability, achievement emotions, and learning of Singapore students. Educational Psychology, 34, 619-634. doi:10.1080/01443410.2014.909008 
Ma, X. (1999). A meta-analysis of the relationship between anxiety toward mathematics and achievement in mathematics. Journal for Research in Mathematics Education, 30, 520-540. doi:10.2307/749772

Mazzocco, M. M. M. (2008). Introduction: Mathematics ability, performance, and achievement. Developmental Neuropsychology, 33, 197-204. doi:10.1080/87565640801982270

Mazzocco, M. M. M., \& Devlin, K. T. (2008). Parts and 'holes': gaps in rational number sense among children with vs. without mathematical learning disabilities. Developmental Science, 11, 681-691. doi:10.1111/j.1467-7687.2008.00717.x

Miller, H., \& Bichsel, J. (2004). Anxiety, working memory, gender, and math performance. Personality \& Individual Differences, 37, 591-606. doi:10.1016/j.paid.2003.09.029

OECD. (2004). Learning for tomorrow's world: First results from PISA 2003. Paris: Author.

OECD. (2014). PISA 2012 results: What students know and can do-Student performance in mathematics, reading, and science (Volume I). Paris: Author. doi:10.1787/9789264201118-en

Osborne, J. W. (2007). Linking stereotype threat and anxiety. Educational Psychology, 27, 135-154. doi:10.1080/01443410601069929

Passolunghi, M. C. (2011). Cognitive and emotional factors in children with mathematical learning disabilities. International Journal of Disability, Development \& Education, 58, 61-73. doi:10.1080/1034912X.2011.547351

Pekrun, R. (2006). The control-value theory of achievement emotions: Assumptions, corollaries, and implications for educational research and practice. Educational Psychology Review, 18, 315-341. doi:10.1007/s10648-006-9029-9

Pekrun, R., Frenzel, A. C., Goetz, T., \& Perry, R. P. (2007). The control-value theory of achievement emotions: An integrative approach to emotions in education. In P. A. 
Schutz \& R. Pekrun (Eds.), Emotions in education (pp.13-36). Amsterdam: Academic Press.

Pekrun, R., Goetz, T., \& Frenzel, A. C. (2005). Academic Emotions Questionnaire Mathematics (AEQ-M) - User's manual. Munich, Germany: University of Munich, Department of Psychology.

Pekrun, R., Goetz, T., Titz, W., \& Perry, R. P. (2002). Academic emotions in students' selfregulated learning and achievement: A program of qualitative and quantitative research. Educational Psychologist, 37, 91-105. doi:10.1207/S15326985EP3702_4

Plenty, S., \& Heubeck, B. G. (2013). A multidimensional analysis of changes in mathematics motivation and engagement during high school. Educational Psychology, 33, 14-30. doi: 10.1080/01443410.2012.740199

Pomerantz, E. M., Altermatt, E. R., \& Saxon, J. L. (2002). Making the grade but feeling distressed: Gender differences in academic performance and internal distress. Journal of Educational Psychology, 94, 396-404. doi:10.1037//0022-0663.94.2.396

Roberts, T.-A. (1991). Gender and the influence of evaluations on self-assessments in achievement settings. Psychological Bulletin, 109, 297-308. doi:10.1037/00332909.109.2.297

Räsänen, P., \& Leino, L. (2005). KTLT - Laskutaidon testi luokka-asteille 7-9 [A Test for Mathematical Skills for Grades 7-9]. Jyväskylä, Finland: Niilo Mäki Instituutti (NMI).

Sakiz, G. (2012). Perceived instructor affective support in relation to academic emotions and motivation in college. Educational Psychology, 32, 63-79. doi:10.1080/01443410.2011.625611 
Sakiz, G., Pape, S. J., \& Hoy, A. W. (2012). Does perceived teacher affective support matter for middle school students in mathematics classrooms? Journal of School Psychology, 50, 235-255. doi:10.1016/j.jsp.2011.10.005

Spencer, S. J., Steele, C. M., \& Quinn, D. M. (1999). Stereotype threat and women's math performance. Journal of Experimental Social Psychology, 35, 4-28. doi:10.1006/jesp.1998.1373

Stephanou, G. (2011). Students' classroom emotions: Socio-cognitive antecedents and school performance. Electronic Journal of Research in Educational Psychology, 9(1), 5-48. Retrieved from http://investigacionpsicopedagogica.org/revista/new/english/index.php

Stipek, D. J., \& Gralinski, J. H. (1991). Gender differences in children's achievement-related beliefs and emotional responses to success and failure in mathematics. Journal of Educational Psychology, 83, 361-371. doi:10.1037/0022-0663.83.3.361

Uusitalo-Malmivaara, L. (2014). Happiness decreases during early adolescence — a study on 12- and 15-year-old Finnish students. Psychology, 5, 541-555. doi:10.4236/psych.2014.56064

Willcutt, E. G., \& Pennington, B. F. (2000). Psychiatric comorbidity in children and adolescents with reading disability. Journal of Child Psychology \& Psychiatry \& Allied Disciplines, 41, 1039-1048. doi:10.1111/1469-7610.00691

Wu, S. S., Willcutt, E. G., Escovar, E., \& Menon, V. (2014). Mathematics achievement and anxiety and their relation to internalizing and externalizing behaviors. Journal of Learning Disabilities, 47, 503-514. doi:10.1177/0022219412473154 